
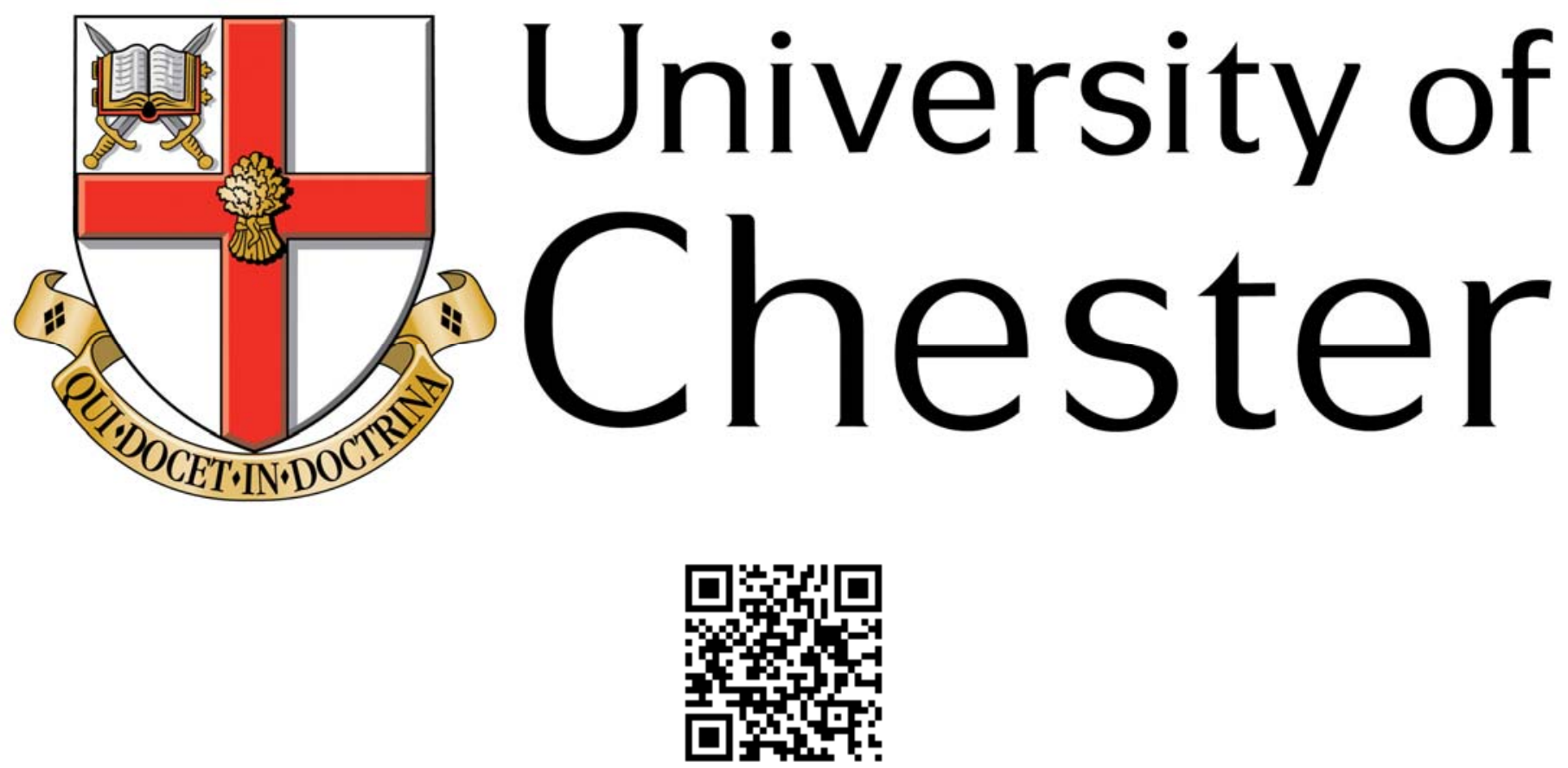

This work has been submitted to ChesterRep - the University of Chester's online research repository

\title{
http://chesterrep.openrepository.com
}

Author(s): Peter Cox

Title: The future of rickshaws: Concluding thoughts and wider issues

Date: 2013

Originally published in: Transfers

Example citation: Cox, P. (2013). The future of rickshaws: Concluding thoughts and wider issues. Transfers, 3(3), 119-123.

http://dx.doi.org/10.3167/TRANS.2013.030308

Version of item: Post-print version

Available at: http://hdl.handle.net/10034/312889 


\section{The Future of Rickshaws}

Concluding Thoughts and Wider Issues

Peter Cox, University of Chester

The contributions to this special section, together with the Introduction, serve a valuable role in bringing to attention a frequently overlooked mobility practice. Particularly welcome is the presence of scholarship from local perspectives within the Western academic context.

Between them, these papers begin to put flesh on what is all too easily framed from European perspectives as an exotic practice of the "other." Yet it is this very possibility of "strangeness" that should alert us to a number of important issues for further consideration. My own perspective here is as an interdisciplinary scholar, working day to day as a sociologist and a researcher into cycling practices, both historical and contemporary. The considerations range between the conceptual and practical, the historical past and the imagined future.

The first question is that relation between colonial pasts and a (post?)colonial present. The proliferation of passenger rickshaw was co-incident with presence of imperial rule across the region. Whether hand-pulled or cycle-rickshaw, the vehicle became a major form of passenger transport under a variety of forms of colonial rule. One cannot ignore the reality that provision of mobility for one class through the direct physical labour of another (inherent to the rickshaw) has the potential to be brutally indicative of the structural inequalities of colonialism. The association between political inequality ( of ruler and subject) and public modes of transport is not simply co-incidental but can also be illustrative of structural social power relations, whether in railway carriages segregated by class or in the visible contrast between rickshaw driver and passenger. 
Indeed, the 1880 engraving reproduced in Gallagher's ground-breaking work on the rickshaw is entitled “coolie cycles for India.” It depicts a pith-helmeted Englishman and his female partner, seated and propelled by “native” labour. ${ }^{1}$ Just as the bicycle in England became associated with the working classes during the interwar period in which the cycle rickshaw first flourished, the identity of the rickshaw as an embodiment of class and caste inequality has had the potential for a long period of sedimentation. In an application for a patent made in England for a horseless hansom carriage in 1895, the horse was simply replaced by a bicycle front end, as adopted in the later cycle rickshaw—one beast of burden for another $?^{2}$ The equation of the colonial subject with animality is doubly degrading. These discursive productions must be excavated, understood and countered if the rickshaw is to be rehabilitated.

Giving voice to the experiences of rickshaw pullers, Samanta and Roy’s paper opens up considerable space for a postcolonial transformation of marginalization from a place of exploitation to one of possible transformation. The emergence of postcolonial scholarship has vitally opened the importance of the revalorization of hidden narratives and identityformations. Framing rickshaw propulsion as a social practice we need to be alert to the multiple meanings that can be attached to rickshaw driving and to its use by passengers. More importantly, perhaps, we need, as Homi K. Bhabha argues, to be aware that "the visibility of the institutions and apparatuses of power" — of which the colonial rickshaw is a clear example-serves to obscure the actual relationships of power. ${ }^{3}$ While acknowledging the real problems of rickshaw pullers, Dubey also notes that the rickshaw suffers a double rejection. ${ }^{4}$ Where capitalism stigmatizes it as a vehicle of backwardness, socialism sees it as a source of exploitation. It should not be surprising to see that the re-imagination of the rickshaw is clearest in a postcolonial analysis. To confuse an external form and practice with the hidden 
institutions of inequality and exploitation is to deflect attention from the greater problems and the necessary sites of struggle.

It is here that we reach the crux of one of the issues underlying all these papers. While the case can, and must, be made that current practices are socially and politically untenable, the problem lies not in the rickshaw as a technology of mobility, but in the multiple inequalities that lie behind existing and historic practices of operation. The argument is made clearer if we approach it from another direction. Again, this is a question arising from the contributions here but necessarily beyond the scope of their address. Put simply, "What is a rickshaw?”

This deceptively simple question hides a wealth of assumptions and unasked considerations. The examples given here, and the dominant assumptions applied in much Western literature, are that the term indicates a vehicle for the carriage of passengers. Thus a hand-pulled rickshaw may be distinguished from any other class of hand-pulled cart, and a cycle rickshaw from a cargo-carrying cycle. Yet why this purely arbitrary distinction? The technology differs little if at all. Steele's Introduction points to the absolute continuity between the carriage of passengers and goods by cycles in the Chinese context. Should moving people by human power be especially degrading, or any more than moving cargo of the same weight? Can and should distinction be made between different styles of transport bicycles? Setting aside considerations of different conditions of carriage that might be applicable, is passenger carriage conceptually separable from the movement of other goods? The bicycle in general suffers from an erroneous assumption of historical obsolescence in the face of motorization according to linear narratives of progress, as Edgerton has pointed out. ${ }^{5}$ Placing the passenger rickshaw into a continuum of human-powered transport, then we see its connection to a much wider narrative of transport history, sociology, and politics. One may more fruitfully see it therefore not as a unique venture but as one among many forms of 
cycling, in turn taking its place as one of a multiplicity of forms of road transport. The passenger cycle rickshaw is simply a human-powered taxi. Taken not only in a broader conceptual context but also in a broader geographical context then we may link the potential of the rickshaw for a future role in sustainable transport systems to the rapid proliferation of cargo-carrying bicycles, tricycles, and quadricycles in northern Europe in the past decade. ${ }^{6}$ Given this approach, hostility to rickshaws can be reframed as part of a broader hostility to non-motorized transport. Yet even here, the linguistic subtleties of naming and othering are at play. The designation accorded implies a lack or incompleteness rather than a self-sufficiency and capability of autonomous transport, which, from a sustainability perspective, could be better termed as fossil-fuel independent. It is true that in territories such as most of the U.S.A. and the U.K., cycling as a means of mundane mobility is far from ubiquitous, and still frequently denigrated. But such attitudes are far from universal and we see the growing embrace and celebration of cycling transport in numerous European states and cities. ${ }^{7}$ A second element to the linking of rickshaws to the wider politics of transport cycling is the necessary contextualization of human-powered transport of all kinds within the broader mix of road users. Although the production of comprehensible and readable research papers requires us to narrow the focus to studies of individual phenomena, we must remember that each of these narratives does not stand in isolation. The fortunes of any transport mode are bound up with a vast number of strands of influence, from planning and political frameworks to employment patterns, wages, and levels of social inequality, as well as infrastructure, spending, and taxation. These factors should also be extended to embrace the cultural elements, including issues around the construction of gender roles, as Hussain and Habiba show.

Consequently, problems of working conditions in the rickshaw industry need to be clearly separated from the idea that the use of human-powered transport is somehow 
inherently degrading. Reform of working conditions and the structures of employment need reform to ensure that this indispensible part of everyday mobility in South Asia continues to play a relevant part in diverse and multiform patterns of urban mobility. A parallel may perhaps be drawn with the role of cycle-messengers in North America and Europe.

Undoubtedly encountering poor working conditions and a sense of marginalization, the remedy to their situation is not abolition but self-organization. ${ }^{8}$

Growing numbers of scholars and activists from Delhi and beyond have argued for almost two decades for dramatic changes to mobility patterns and the current trajectory of evergrowing motorization. ${ }^{9}$ As Sunita Narain, of the Centre for Science and Environment in New Delhi, puts it, "the only option for our cities is to reinvent mobility so that we do not have to drive.”10 Moreover, globally linked NGO’s such as ITDP India are actively pursuing projects to support rickshaw driver's organization and the integration of Rickshaw within existing and future transport planning. ${ }^{11}$

These voices represent the continuation of a distinctly emancipatory narrative akin to that identified by Gijs Mom in relation to the resurgence of interest in European studies in cycling history and practice. ${ }^{12}$ Cycle activists understand the bicycle not simply as transport but as literally a vehicle of social change. We might further extend this analysis by linking back to the previous connection made with postcolonial perspectives. The position of the rickshaw is doubly marginalized. First, there is the marginalization of voice, addressed by Samanta and Roy. Second, the rickshaw is not only marginalized in conceptual terms from transport planning, but also in physical space to the edges of road space, or from major highways altogether. Yet this marginalization and relative invisibility in dominant discourses may also serve as a source of strength. As bell hooks argues convincingly and passionately, marginality simultaneously exists as a site of resistance and a conceptual space in which critique can emerge and be nurtured. ${ }^{13}$ From outside of the mainstream, a position can be 
forged that does not exclusively concentrate on the pragmatic management of existing problems and the integration of currently marginalized groups and practices into the dominant patterns. It also allows the envisaging of radical alternatives. Providing an opportunity for rickshaw pullers to “talk back” (in hooks’ phrase) affirms their reality and prevents their reduction to a category of "problem," to be solved by others in positions of power.

The study of the rickshaw provides not only an insight into the specific problems of a particular mobility sector but raises wider questions both for the politics of the study of urban mobilities and the degree to which mobilities study engages with other theoretical perspectives in its interdisciplinary complexity.

\section{Author Biography}

Peter Cox is a Senior Lecturer in Sociology at the University of Chester. Prior to re-entering academia, Peter ran his own cycle business and was involved in a range of campaigning and community organising projects. Since completing his doctoral thesis (2002) his research work has specialised in the area of social change and sustainable transport, especially the vital contribution of cycling and its importance for social justice. He is author of Moving People: Sustainable Transport Development (Zed Books, 2010 [also as In Bewegung: Ist nachhaltiger Personentransport möglich? WBG, 2012]) and was a founder member of the Cycling and Society Research Group, co-editing (with Dave Horton and Paul Rosen) Cycling and Society (Ashgate 2007) as an outcome of this group’s work.

\footnotetext{
${ }^{1}$ Rob Gallagher, The Rickshaws of Bangladesh (University of Dhaka Press, 1992), 48 2 “A Handsome Horseless Hansom,” The Wheel and Cycling Trade Review (New York and Chicago) August 30, 1895, 30. Notably, this application places a second rider behind the cab as per a hansom cab driver.
} 
${ }^{3}$ Homi K. Bhabha, “The Other Question: Difference Discrimination and the Discourse of Colonialism,” in Out There: Marginalization and Contemporary Cultures, ed. Russell Ferguson et al. (New York: New Museum of Contemporary Art, 1990), 71-87, here: 85. ${ }^{4}$ Abhay Kumar Dubey, “The Rickshaw Refuses to Go Away: The Struggle of the Cotraveller of Asian Modernity,” in The Saga Of Rickshaw, ed. R. Ravi (Delhi: VAK, 2006), 29-65, here: 41.

${ }^{5}$ David Edgerton, The Shock of the Old: Technology and Global History Since 1900 (London: Profile, 2006).

${ }^{6}$ For an overview of European cargo cycles see P. Cox and R. Rzewnicki, "Between Store and Home: Distributing Consumer Goods by Cycle,” in Cycling Cultures, ed. P. Cox (University of Chester Press, forthcoming 2014).

${ }^{7}$ See for example contributions for the Velo-City series of conferences, e.g. Velo-City 2013 Vienna http://velo-city2013.com/ (accessed July 1, 2013).

${ }^{8}$ Ben Fincham, “Bicycle Couriers in the 'New’ Economy”, Cardiff School of social sciences Working Paper Series, No. 46, 2004. For an example of messenger organizations, see The Bicycle Messenger Emergency Fund, at http://www.bicyclemessenger.org/ (accessed July 1, 2013).

${ }^{9}$ See e.g. Anju Sharma and Anumita Roychowdhury, Slow Murder, The Deadly Story of Vehicular Pollution in India (New Delhi: Centre for Science and Environment, 1996). ${ }^{10}$ Sunita Narain “Editorial: Pedestrian Questions,” Down to Earth, June 30, 2013. Online version at http://www.downtoearth.org.in/content/pedestrian-questions (accessed July 1, 2013). ${ }^{11}$ IInstitute for transportation and Development Policy, ITDP Annual Report 2010 . Online version at http://www.itdp/uploads/ITDP_AR_10.pdf (accessed July 1, 2013) 
${ }^{12}$ Gijs Mom, “'Historians Bleed Too Much’: Recent Trends in the State of the Art in Mobility History,” in Peter Norton, Gijs Mom, Liz Millward and Mathieu Flonneau (eds.), Mobility in History: Review and Reflections (Lausanne: Editions Alphil, 2011), 15-30.

${ }^{13}$ bell hooks, “Marginality as a Site of Resistance,” in Out There: Marginality and contemporary cultures, ed. Russell Ferguson et al. (Cambridge, MA: MIT Press, 1990), 341344. 